\title{
Kinetics of Sorption of Pendimethalin on Soil Samples Obtained from the Banks of Rivers Katsina-Ala and Benue, Central Nigeria
}

\author{
Justin Kpagh, Rufus Sha'Ato*, Raymond A. Wuana, Terrumun A. Tor-Anyiin \\ Department of Chemistry, University of Agriculture, Makurdi, Nigeria \\ Email: "rshaato@gmail.com
}

Received 27 October 2015; accepted 5 January 2016; published 8 January 2016

Copyright $(\subset 2016$ by authors and Scientific Research Publishing Inc.

This work is licensed under the Creative Commons Attribution International License (CC BY). http://creativecommons.org/licenses/by/4.0/

(c) (i) Open Access

\begin{abstract}
Kinetics of the sorption of the herbicide, pendimethalin (3,4-Dimethyl-2,6-dinitro- $N$-pentan-3-ylaniline) on four soil samples obtained from the banks of Rivers Benue and Katsina-Ala, in Central Nigeria was studied by contacting $5.0 \mathrm{~g}$ soil samples with $100 \mathrm{~mL} 7 \times 10^{-6} \mathrm{M}$ herbicide solution. The sorption was monitored by following the herbicide concentration in the aqueous phase spectrophotometrically at one hour intervals for 5 hours $\left(\right.$ at $25^{\circ} \mathrm{C}, 35^{\circ} \mathrm{C}, 45^{\circ} \mathrm{C}, 55^{\circ} \mathrm{C}$ and $65^{\circ} \mathrm{C}$, respectively). Pseudo-first order kinetics treatment of the data showed that sorption rates as well as the accompanying activation energies were low, indicating that physical adsorption is the operative mechanism for its retention in the soils and that the herbicide tended to reside more in the aqueous phase, which raised its potential to contaminate natural water systems, when applied on the field.
\end{abstract}

\section{Keywords}

Kinetics, Sorption, Pendimethalin, Soil, Nigeria

\section{Introduction}

The use of herbicides in the Lower Benue Valley $\left(6^{\circ} 15^{\prime}-8^{\circ} 00^{\prime} \mathrm{N}\right.$; $\left.6^{\circ} 15^{\prime}-11^{\circ} 00^{\prime} \mathrm{E}\right)$ in Central Nigeria is not only on the increase, but also indiscriminate. This is because the area has a predominantly agrarian economy and one of the major problems farmers face is the aggressive growth of weeds which negatively affects farm produce. Among other herbicides [1], pendimethalin (3,4-Dimethyl-2,6-dinitro- $N$-pentan-3-yl aniline, Figure 1), a preemergence herbicide effective against many annual grasses and broadleaf weeds enjoys widespread use in the area.

"Corresponding author.

How to cite this paper: Kpagh, J., Sha'Ato, R., Wuana, R.A. and Tor-Anyiin, T.A. (2016) Kinetics of Sorption of Pendimethalin on Soil Samples Obtained from the Banks of Rivers Katsina-Ala and Benue, Central Nigeria. Journal of Geoscience and Environment Protection, 4, 37-42. http://dx.doi.org/10.4236/gep.2016.41004 


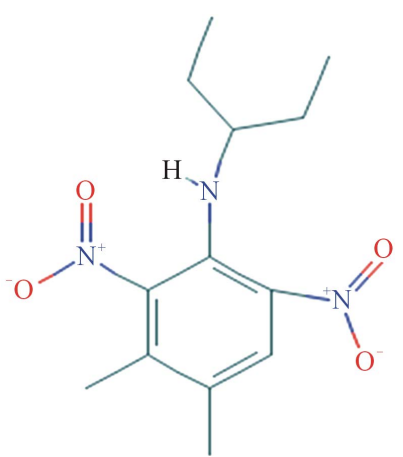

Figure 1. Structure of pendimethalin (3,4-dimethyl-2,6-dinitro- $N$-pentan-3-yl aniline).

Being a soil-applied herbicide, once applied, it is taken up by the roots and/or hypocotyls of the target weeds, interfering with their growth, and eventually killing them. It has been noted, for a long time, that the efficacy of soil-applied herbicides depends, in part, on soil type [2]. Performance is further influenced by herbicide adsorption. According to Wauchope and Koskinen [3], sorption is a major factor controlling herbicide activity, mobility and persistence in soil. It also determines the quantity of herbicide in soil solution and thus the amount that is available to be leached [4]. Thus, for effective assessment of the mobility and pollution potentials of herbicides to be made and for better understanding of the fate of these chemicals in soil, a good knowledge of their sorption behaviour, including kinetics, in different soil types is desired. While pendimethalin is known to adsorb strongly to soil organic matter and clay, soils in the Lower Benue Valley are generally low in organic matter and clay [5]. It is, therefore, expected that this herbicide effective against many annual grasses and broadleaf weeds may be highly mobile in them and so may pose a surface and groundwater contamination hazard in the area. Considering that it is a suspected carcinogen [6], it is not subject to microbial degradation and only slight losses of the herbicide may be expected from photodecomposition and volatilization on the field (its soil half-life is found to be 90 days [7], it is imperative that its fate in the Lower Benue Valley environment, where it is widely used, is investigated. The aim of this study is, therefore, to investigate the sorptive behaviour of pendimethalin in selected soils in the area, since there is little or no information on this in the literature.

\section{Materials and Methods}

\subsection{Soil Sampling and Preparation}

Soil samples were taken at the surface horizon $(0-25 \mathrm{~cm})$ at four different locations along the banks of Rivers Benue and Katsina-Ala, where both rain-fed and irrigation agriculture (vegetable cropping) is very active. The samples were identified as follows:

1) RB1 Benue River bank (7.746756N 8.61755E)

2) RB2 Benue River bank (7.748797N 861755E)

3) RKA1 Katsina-Ala River bank (7.194838N 9.287592E)

4) RKA2 Katsina-Ala River bank (7.154097N, 9.285760E)

The whole soil samples, each weighing $1.5 \mathrm{~kg}$, were taken to the Chemistry Laboratory, University of Agriculture, Makurdi, in black polythene bags and subsequently spread in a dust-free wooden cupboard to air-dry. After air-drying (7 days), the samples were gently crushed and sieved using a $2 \mathrm{~mm}$ sieve/shaker. The $<2 \mathrm{~mm}$ soil fraction was retained for sorption studies.

\subsection{Pendimethalin}

The commercial formulation of the herbicide (500EC i.e. $500 \mathrm{~g} / \mathrm{L}$ ) as used by farmers, was purchased from Lado Agrochemicals Company, Katsina-Ala. This was used without purification to simulate the condition in which it reaches the soil in practice.

\subsection{Determination of Some Physico-Chemical Properties of Soil Samples}

Laboratory soil samples moisture content was determined using the method employed by Charturvediand Sankar 
[8]; pH was determined using a portable pH meter (Jenway Digital Meter model 3505) after calibration at pH 4 and 7. Electrical conductivity was measured directly using a portable conductivity meter (HACH C0150 model). Organic matter was determined using the dichromate method, while Cation Exchange Capacity (CEC) was determined at $\mathrm{pH} 7$ using $1 \mathrm{M}$ ammonium acetate. In each case, three replicate readings were taken and the mean calculated.

\subsection{Sorption Kineticsstudies}

A wavelength scan of the herbicide solution was done using chloroform from $370 \mathrm{~nm}$ to $480 \mathrm{~nm}$ to determine the wavelength of maximum absorption $\lambda_{\max }$ for use in the sorption experiments; this was found to be $416 \mathrm{~nm}$ compared to $437 \mathrm{~nm}$ in the literature [9]. The experimental $\lambda_{\max }$ was used in this study. For each soil sample, 5.0 grams were placed in a 250-mL glass-stoppered conical flask. Hundred (100) mL of standard pendimethalin solution $\left(7 \times 10^{-6} \mathrm{M}\right)$ was added and the volume made up to $250 \mathrm{~mL}$ with distilled water. Five sets of experiments were conducted at $25^{\circ} \mathrm{C}, 35^{\circ} \mathrm{C}, 45^{\circ} \mathrm{C}, 55^{\circ} \mathrm{C}$ and $65^{\circ} \mathrm{C}$ using an incubator. At one-hour intervals, aliquots of the solutions were withdrawn, cooled, centrifuged and the herbicide concentration in the supernatant determined spectrophotometrically using the UV-Visible spectrophotometer at $416 \mathrm{~nm}$. At each stage, the difference between the concentration of pendimethalin added and the one found in the supernatant was used to calculate the amount of the herbicide adsorbed after definite time intervals. All readings were triplicated and mean values used.

\section{Results}

Table 1 gives the physicochemical properties of the soil samples: the low moisture content in storage showed that the soils were well dried as at the point of analysis; the $\mathrm{pH}$ values indicate the soils are fairly acidic under field conditions, as their CECs are typical of soils in the Lower Benue Valley [10]. While the soils from the banks of the River Benue (RB1 and 2) have high clay contents, the soils from the banks of River Katsina-Ala (RKA1 and 2) are largely sandy loam in nature. Overall, the soils have organic matter content typical of their alluvial origins. Table 2 shows kinetic parameters (in the temperature range of $25^{\circ} \mathrm{C}-65^{\circ} \mathrm{C}$ ) which were calculated from slopes of pseudo-first order kinetic plots (of natural logarithm of amount of pendimethalin adsorbed (Q) versus time ( $t$, in hours), in accordance with Equation (1).

$$
\ln Q=k_{r}
$$

where, $k_{r}$ is the pseudo-first order rate constant. The linearity of the plots (with negative slopes), gave support to the primary assumption that the sorption considered in this study followed first order kinetics [11]. From the rate constants, the sorption half-life (a measure of the persistence in the aqueous phase) of pendimethalin was calculated appropriately (Equation (2)).

$$
t_{1 / 2}=\frac{0.693}{k_{r}}
$$

Application of the linearized Arrhenius Equation (3) (plots of $\ln k_{r}$ vs. $\frac{1}{T}$, where, $T=$ absolute temperature)

Table 1. Physicochemical properties of soil samples taken from the banks of Rivers Benue and Katsina-Ala, Central Nigeria.

\begin{tabular}{ccccccc}
\hline Soil sample & $\begin{array}{c}\text { Moisture } \\
\text { content (\%) }\end{array}$ & $\mathrm{pH}$ & $\begin{array}{c}\text { Electrical } \\
\text { conductivity } \\
\mu \mathrm{s} / \mathrm{cm}\end{array}$ & \% Clay & $\begin{array}{c}\text { Organic } \\
\text { matter }(\%)\end{array}$ & $\begin{array}{c}\text { Soil CEC at pH7 } \\
(\mathrm{cmol}(+) \mathrm{kg})\end{array}$ \\
\hline RB1 & 1.03 & 5.8 & 59.60 & 45.7 & 8.29 & 3.63 \\
RB2 & 1.06 & 5.6 & 37.50 & 50.6 & 8.17 & 3.80 \\
RKA1 & 0.44 & 6.1 & 46.03 & 16.2 & 4.58 & 0.82 \\
RKA2 & 0.72 & 6.3 & 33.47 & 12.2 & 4.47 & 3.41 \\
\hline
\end{tabular}


Table 2. Parameters derived from pseudo-first order kinetic plots for pendimethalin sorption on soil samples taken from the banks of Rivers Benue and Katsina-Ala, Central Nigeria.

\begin{tabular}{|c|c|c|c|c|c|}
\hline 1/Temp & Slope & $k_{r}\left(\right.$ hour $\left.^{-1}\right)$ & $\ln k_{r}$ & $t_{1 / 2}$ (hours) & $E^{\ddagger}\left(\mathrm{kJ} \cdot \mathrm{mol}^{-1}\right)$ \\
\hline \multicolumn{6}{|c|}{ Pendimethalin sorption on soil sample RB1 } \\
\hline 3.35E-03 & -0.0598 & 0.137 & -1.98 & 5.05 & \\
\hline 3.25E-03 & -0.0627 & 0.144 & -1.93 & 4.81 & \\
\hline 3.14E-03 & -0.0265 & 0.061 & -2.79 & 11.4 & 10.6 \\
\hline 3.05E-03 & -0.0577 & 0.132 & -2.01 & 5.25 & \\
\hline $2.96 \mathrm{E}-03$ & -0.0837 & 0.192 & -1.64 & 3.61 & \\
\hline \multicolumn{6}{|c|}{ Pendimethalin sorption on soil sample RB2 } \\
\hline 3.35E-03 & -0.0749 & 0.172 & -1.75 & 4.03 & \\
\hline 3.25E-03 & -0.0540 & 0.124 & -2.08 & 5.59 & \\
\hline 3.14E-03 & -0.0604 & 0.139 & -1.97 & 4.98 & 10.6 \\
\hline 3.05E-03 & -0.0450 & 0.103 & -2.26 & 6.73 & \\
\hline 2.96E-03 & -0.0633 & 0.145 & -1.92 & 4.78 & \\
\hline \multicolumn{6}{|c|}{ Pendimethalin sorption on soil sample RKA1 } \\
\hline 3.35E-03 & -0.0762 & 0.175 & -1.74 & 3.96 & \\
\hline $3.25 \mathrm{E}-03$ & -0.0556 & 0.128 & -2.05 & 5.41 & \\
\hline 3.14E-03 & -0.0615 & 0.141 & -1.95 & 4.91 & 10.3 \\
\hline 3.05E-03 & -0.0590 & 0.135 & -1.99 & 5.13 & \\
\hline 2.96E-03 & -0.0602 & 0.138 & -1.97 & 5.02 & \\
\hline \multicolumn{6}{|c|}{ Pendimethalin sorption on soil sample RKA2 } \\
\hline 3.35E-03 & -0.0696 & 0.160 & -1.83 & 4.33 & \\
\hline $3.25 \mathrm{E}-03$ & -0.0624 & 0.143 & -1.93 & 4.85 & \\
\hline 3.14E-03 & -0.0621 & 0.143 & -1.94 & 4.85 & 10.9 \\
\hline 3.05E-03 & -0.0476 & 0.109 & -2.21 & 6.36 & \\
\hline 2.96E-03 & -0.0500 & 0.115 & -2.16 & 6.03 & \\
\hline
\end{tabular}

$$
\ln k_{r}=\ln A-\frac{E^{\ddagger}}{R T}
$$

gave access to the activation energy $\left(E^{\ddagger}\right)$ for the sorption process in the soils.

\section{Discussion}

Of the four soil samples studied, percentage clay was highest in sample RB2 followed by sample RB1, RKA1 and RKA2 in that order (Table 1). Soil samples RB1 and RB2 with the highest percentage clay also had the highest percentage organic matter. For example, it was earlier noted that the more clay or organic matter present in a soil, the higher the CEC [12]. This was the case for soil samples RB1 and RB2, which also showed high water - holding capacities (moisture content in storage of circa $1 \%$ compared to $<1 \%$ for the other soil samples). The $\mathrm{pH}$ values of all the soil samples were less than 7 , and generally within the same acidic range (Table 1). On the whole, the soils have properties that are expected of soils in this area of Nigeria.

Sorption rate constants obtained from the pseudo-first order kinetics treatment of the data were low (Table 2) 
and half-lives relatively long, although they showed no clear trend for samples RKA1 and RKA2. However, adsorption rates on samplesRB1 and RB2 showed an increase in adsorption rate with temperature, similar to observations by [11] who studied dazomet adsorption on natural adsorbents. This trend was in agreement with the fact that the amount of a pesticide adsorbed in soils is related to the organic carbon contents of the soils [13]. Torrents and Jayasundera [14] also conducted the sorption study of non-ionic pesticides and found that the intensity of adsorption was a function of herbicide and clay contents. Nevertheless, Shimizu and Liljestrand [15] reported that there was no relationship between sorption and organic carbon in soils in the case of low organic carbon soils. Therefore, soil organic carbon and clay contents may not have been the only factors relevant to pendimethalin adsorption in this study. This fact may have been responsible for the unclear adsorption trend in soil samples RKA1 and RKA2.

The activation energies $\left(E^{\ddagger}\right)$ obtained in the study ranged from $10.3 \mathrm{~kJ} \cdot \mathrm{mol}^{-1}$ to $10.9 \mathrm{~kJ} \cdot \mathrm{mol}^{-1}$. According to Bansal [16], activation energies of $10-28 \mathrm{~kJ} \cdot \mathrm{mol}^{-1}$ represent physical adsorption. Since the calculated values of $E^{\ddagger}$ were within this range, it implied that only physical adsorption of the herbicide on soil surfaces must have taken place. This was expected, looking at the molecular structure of the herbicide. Low sorption ensured a longer residency time of the herbicide in the aqueous phase (half-lives of about 6 hours generally), suggesting that pendimethalin could be fairly mobile (susceptible to leaching transport) in the soils under study and hence could easily contaminate ground- and surface water resources in the area.

\section{Conclusion}

In conclusion, rate constants, half-lives and activation energies of adsorption of pendimethalin on four soil samples obtained from the Lower Benue Valley in Central Nigeria were determined in this study, along with some physicochemical parameters of the soils. Physicochemical parameters showed significant variations in line with what is known about tropical soils. Values of sorption rate constants, half-lives and activation energies indicated low adsorption rates on soil samples. Activation energies indicated physical adsorption of the herbicide. On the whole, results in the study showed that the herbicide has potential to cause contamination of surface and ground waters by its persistence through leaching and runoff because of its low adsorption.

\section{References}

[1] Kughur, P.G. (2012) The Effects of Herbicides on Crop Production and Environment in Makurdi Local Government Area of Benue State, Nigeria. Journal of Sustainable Development in Africa, 14, 206-216.

[2] Stevenson, F.J.J. (1972) Organic Matter Interactions Involving Herbicides in Soil. Journal of Environmental Quality, 1, 333-343. http://dx.doi.org/10.2134/jeq1972.00472425000100040001x

[3] Wauchope, R.D. and Koskinen, W.C. (1983) Adsorption Desorption Equilibrium of Herbicides in Soil: Thermodynamic Perspective. Weed Science, 31, 504-512.

[4] Bailey, G.W. and White, J.L. (1970) Factors Influencing the Adsorption, Desorption and Movement of Pesticides in Soils. Residue Review, 32, 29-92. http://dx.doi.org/10.1007/978-1-4615-8464-3_4

[5] Sha'Ato, R., Ajayi, S.O. and Ojanuga, A.G. (2012) Total and Extractable Copper, Iron, Manganese and Zinc in Major Agricultural Soils in the Lower Benue Valley, Central Nigeria and the Concept of Extractant Efficiency. Nigerian Journal of Chemical Research, 17, 59-62.

[6] Coats, J.R. and Yamamoto, A. (2003) Environmental Fate and Effect of Pesticides. Symposium 853, ACS, Washington. http://dx.doi.org/10.1021/bk-2003-0853.fw001

[7] United States Department of Agriculture (1990) Soil Conservation Service. Pesticide Properties Database, New York.

[8] Charturvedi, R.K. and Sankar, K. (2006) Laboratory Manual for Physiochemical Analysis of Soil, Water and Plants. Wildlife Institute of India, Dehradun, 6-9.

[9] Pest Management Regulatory Agency (2007) A. L 6605C, Ontario, Canada pp 7.

[10] Sha'Ato, R., Ojanuga, A.G. and Ajayi, S.O. (2000) Forms and Profile Distribution of Potassium in Typical Soils of the Lower Benue Valley of Nigeria. Communications in Soil Science and Plant Analysis, 31, 437-453.

[11] Sismanoglu, T., Ercag, A., Pura, S. and Ercag, E. (2004) Kinetics and Isotherms of Dazomet Adsorption on National Adsorbents. Journal of the Brazilian Chemical Society, 15, 669-675. http://dx.doi.org/10.1590/S0103-50532004000500010

[12] Agronomy Fact Sheet No. 22 (2007) Dept. of Crop and Soil Sciences. Cornell University Co-Operative Extension, 1-2.

[13] Kanazawa, J. (1989) Relationship between the Soil Sorption Constants Pesticide and Their Physicochemical Properties. 
Environmental Toxicology and Chemistry, 8, 477-484. http://dx.doi.org/10.1002/etc.5620080604

[14] Torrents, A. and Jayasundera, S. (1997) The Sorption of Nonionic Pesticides onto Clays and the Influence of Natural Organic Carbon. Chemosphere, 35, 1549-1565. http://dx.doi.org/10.1016/S0045-6535(97)00206-3

[15] Shimizu, Y. and Liljestrand, H.M. (1990) Sorption of Polycyclic Aromatic Hydrocarbons onto Natural Solids: Determination by Fluorescence Quenching Method. Water Science \& Technology, 23, 427-436.

[16] Bansal, O.P. (2004) Kinetics of İnteraction of Three Carbamate Pesticides with Indian Soils: Aligrah District. Pest Management Science, 60, 1149-1155. http://dx.doi.org/10.1002/ps.915 